\title{
Tổng hợp Naphtol as-thế Photphat làm cơ chất nhuộm Photphataza bạch cầu người
}

\author{
Trần Thị Hoa ${ }^{1, *}$, Trần Thị Thanh Tâm ${ }^{1}$, \\ Nguyễn Đình Duy ${ }^{3}$, Lưu Văn Bôi ${ }^{1}$, Trần Văn Tính ${ }^{2}$ \\ ${ }^{1}$ Khoa Hóa học, Truòng Đại học Khoa học Tự nhiên, ĐHQGHN, 19 Lê Thánh Tông, Hà Nội, Việt Nam \\ ${ }^{2}$ Trung tâm Huyết học - Truyền máu, Bệnh viện 19-8 \\ ${ }^{3}$ Truờng chuyên Khoa học Tự nhiên, ĐHQGHN, 334 Nguyễn Trãi, Hà Nội, Việt Nam \\ Nhận ngày 04 tháng 5 năm 2017 \\ Chỉnh sửa ngày 12 tháng 5 năm 2017; Chấp nhận đăng ngày 28 tháng 6 năm 2017
}

\begin{abstract}
Tóm tắt: Naphtol AS-BI photphat được ứng dụng làm cơ chất nhuộm hóa học tế bào để phân loại dòng bệnh bạch cầu kinh và phân biệt tế bào Lympho $\mathrm{T}$ trong bệnh bạch cầu cấp. Để bổ sung nguồn cơ chất cóđộ nhạy và độ đặc hiệu cao với giá thành hợp lý, đã tiến hành tổng hợp dãy 3[(N-aryl)cacbamoyl]-naphtalen-2-yl dihidroxyphotphat (Naphtol AS-X photphat) bằng phản ứng của các dẫn xuất Naphtol $\mathrm{AS}-\mathrm{X}$ với $\mathrm{POCl}_{3}$, sau đó tiến hành thủy phân. Kết quả sử dụng 6 hợp chất Naphtol AS-thế photphat (naphtol AS-X photphat) tổng hợp được làm cơ chất nhuộm photphataza đặc hiệu bạch cầu cho thấy rằng tất cả các cơ chất đều dương tính với các tế bào bạch cầu trung tính, bạch cầu ưa axit và bạch cầu ưa bazơ.
\end{abstract}

Tù khóa: Naphthol AS-BI phosphate, Alkaline phosphatase, acute leukemia.

\section{Mở đầu}

Bệnh bạch cầu là một nhóm bệnh lý ác tính hệ thống tạo máu [1]. Số người mắc bệnh có xu hướng ngày càng tăng với đặc điểm có sự tăng sinh bất thường không thể kiểm soát của các tế bào bạch cầu chưa trưởng thành lấn át các tế bào bình thường trong tủy xương và máu ngoại vi. Theo thống kê của tổ chức Sức khỏe Mỹ năm 2016, tỉ lệ mắc bệnh ung thư bạch cầu là tương đối cao chiếm $4 \%$ và đứng thứ 9 trong các bệnh ung thư mắc ở nam giới, chiếm $3 \%$ và

\footnotetext{
*Tác giả liên hệ. ĐT.: 84-1664723800.

Email: tranthihoa_t58@hus.edu.vn

https://doi.org/10.25073/2588-1140/vnunst.4494
}

đứng thứ 8 trong các bệnh ung thư mắc ở nữ giới [2].

Hiện nay, việc phân loại dòng tế bào ung thư máu theo tiêu chuẩn FAB dựa trên kết quả của ba phương pháp: miễn dịch, di truyền và nhuộm hóa học tế bào [3]. Nhuộm hóa học tế bào là kỹ thuật dễ thao tác, không đòi hỏi máy móc thiết bị đắt tiền và giá thành rẻ nên được ứng dụng trong nhiều bệnh viện, cơ sở nghiên cứu. Nhuộm hóa học tế bào gồm nhiều kỹ thuật, trong đó nhuộm photphataza bạch cầu dùng để phân biệt bệnh bạch cầu kinh dòng tủy và bạch cầu cấp dòng tế bào tóc (hairy cell). Cơ chất được sử dụng là Naphtol AS-BI photphat có độ nhạy và độ đặc hiệu cao nhưng phải nhập ngoại với giá thành đắt. Ngoài ra, việc vận chuyển cơ chất gặp khó khăn do phải bảo quản phải dưới - 
$20^{\circ} \mathrm{C}$ [4]. Vì vậy, tổng hợp dãy Naphtol AS-X photphat thế làm cơ chất nhuộm photphataza dùng trong chẩn đoán, điều trị bệnh bạch cầu người thay thế hóa chất nhập ngoại là đề tài có ý nghĩa khoa học và thực tiê̂̃n cần thiết.

\section{Thực nghiệm và phương pháp nghiên cứu}

\subsection{Hóa chất và thiết bị}

Hóa chất:

Các Naphtol AS-D photphat 95\%, Naphtol AS-OL photphat 95\%, Naphtol AS-CA photphat 98\%, Naphtol AS-BS photphat 99,3\%, Naphtol AS-BO photphat 99,42\%, Naphtol ASLC photphat 99,41\%, $\mathrm{Na}_{2} \mathrm{PO}_{4} 99 \%$, loại $\mathrm{P}$, $\mathrm{KH}_{2} \mathrm{PO}_{4}$, loại $\mathrm{P}$, sản phẩm của Sigma Aldrich; muối điazo: Fast red violet LB salt là sản phẩm của Acros; THF $99 \%$ và $\mathrm{POCl}_{3} 99 \%$, sản phẩm của Merk; Pyridin 99\%, $\mathrm{HCl} 36,7 \%$, sản phẩm của Trung Quốc; thiết.

Các hóa chất trên được tinh chế lại khi cần

Dụng cụ và thiết bị:

Phổ hồng ngoại (IR) được đo trên máy FTIR Affinity trong khoảng 400- $4000 \mathrm{~cm}-1$ tại khoa Hóa học, Đại học Khoa học Tự nhiênĐHQGHN; mẫu được ép viên với $\mathrm{KBr}$;

Phổ khối lượng (MS) được đo trên máy LCMSD-Trap-SL của hãng Agilent Technologies (Mỹ), Viện Hóa học -Viện Khoa học và Công nghệ Việt Nam;

Phổ cộng hưởng từ proton được đo trên máy ADVANCE Spectrometer (Bruker $500 \mathrm{Mv}$ ), tần số $500 \mathrm{MHz}$, tại khoa Hóa học, trường Đại học Khoa học Tự nhiên-ĐHQGHN;

Cân phân tích Sartorius độ chính xác $10^{-4}$ gram, tại Bệnh viện 19-8;

Máy đo điểm nóng chảy Omega SMP40, phòng thí nghiệm Hóa dược, Khoa Hóa học, Đại học Khoa học Tự nhiên- ĐHQGHN;

Ủ nhiệt tiêu bản nhuộm bằng máy điều nhiệt CW-20GS $\left(0-500^{\circ} \mathrm{C}\right)$ tại nhiệt độ $37^{\circ} \mathrm{C}$ của Hàn Quốc, độ chính xác $\pm 0.1^{\circ} \mathrm{C}$, tại bệnh viện 19-8;
Soi tiêu bản bằng kính hiển vi hai mắt Nikon với độ phóng đại 1.000 lần có gắn máy chụp ảnh, tại viện 19-8.

Phương pháp nghiên cứu: tổng hợp hữu cơ và nhuộm hóa học tế bào.

\subsection{Thục nghiệm}

\subsubsection{Tổng hợp dãy co chất Naphtol $A S-X$} photphat

Quy trình tổng hợp Naphtol AS-D photphat:

Hòa tan 1,00 gam Naphtol AS-D ( 3,426 mmol) trong $10 \mathrm{ml}$ dung môi pyridin khan ( được làm khan bằng $\mathrm{NaOH}$ ) sau đó làm lạnh hỗn hợp phản ứng đến $0^{\circ} \mathrm{C}$. Nhỏ từ từ từng giọt $0,481 \mathrm{ml}$ dung dịch $\mathrm{POCl}_{3}(5,139 \mathrm{mmol})$, khuấy đều trong $24 \mathrm{~h}$, giữ nhiệt độ tại $0^{\circ} \mathrm{C}$. Cho $15 \mathrm{ml}$ nước đá vào hốn hợp, điều chỉnh $\mathrm{pH}$ của dung dịch ở $\mathrm{pH}=8$ bằng dung dịch $\mathrm{NaOH} 1 \mathrm{M}$ và khuấy đều khoảng 15 phút để phản ứng thủy phân xảy ra hoàn toàn, thu được dung dịch chứa dinatri 3-[(N-aryl) cacbamoyl]naphthalen-2-yl photphat. Acid hóa hỗn hợp bằng dung dịch $\mathrm{HCl} 0,1 \mathrm{M}$ cho tới khi xuất hiện kết tủa $(\mathrm{pH}=2)$. Lọc thu kết tủa. Phần dịch lọc được pha loãng bằng lượng nước đá theo tỷ lệ $1: 1$, khuấy mạnh, thu thêm kết tủa. Gộp 2 phần kết tủa với nhau và rửa bằng dung dịch $\mathrm{HCl}$ loãng thu được cơ chất naphthol AS-X photphat thô dạng rắn màu nâu. Tỉnh chế cơ chất bằng cách hòa tan naphthol AS-X photphat thô vào $\mathrm{NaOH} 1 \mathrm{M}$, thêm dung môi tetrahydrofuran (THF) theo tỷ lệ THF: nước $=1: 5$, sau đó làm lạnh dung hồn hợp ở $2-4^{\circ} \mathrm{C}$ và axit hóa bằng $\mathrm{HCl} 0,1 \mathrm{M}$ đến $\mathrm{pH}=4$. Lọc thu cơ chất naphthol AS-X photphat tinh khiết.

Hiệu suất sản phẩm là 0,5414 gam (44\%).

Tương tự đã tiến hành tổng hợp các dẫn xuất naphtol AS-X photphat khác.

Kết quả tổng hợp, một số hằng số hóa lý và các dự kiện phổ của các cơ chất tổng hợp được thể hiện trong các bảng 1 và 2 .

\subsubsection{Nhuộm hóa học tế bào kỹ thuật} nhuộm photphataza

Các cơ chất tổng hợp được sử dụng làm cơ chất cho kỹ thuật nhuộm photphataza. 
Quy trình nhuộm hóa học tế bào được tiến hành 4 bước theo tài liệu [5].

Bước 1: Cố định tiêu bản trong dung dịch cố định, rửa kỹ bằng nước cất, để khô;

Bước 2: Nhúng tiêu bản trong dung dịch nhuộm 30 phút ở nhiệt độ $37^{\circ} \mathrm{C}$. Dung dịch nhuộm được pha chế (tính cho một tiêu bản nhuộm) như sau:

\begin{tabular}{ll}
\hline Dung dịch cơ chất: & $100 \mu \mathrm{l}$ \\
\hline Dung dịch muối điazo: & $100 \mu \mathrm{l}$ \\
Dung dịch đệm: & $2.000 \mu \mathrm{l}$ \\
Tổng thể tích: & $2.200 \mu \mathrm{l}$ \\
\hline
\end{tabular}

Bước 3: Nhuộm nhân và nền bằng dung dịch Hemtoxylin 5 phút ở nhiệt độ $37^{\circ} \mathrm{C}$, rửa sạch tiêu bản, để khô và đọc tiêu bản dưới kính hiển vi với độ phóng đại 1000 lần.

Kết quả nhuộm được đánh giá bằng bằng phương pháp phân độ và tính điểm theo quy trình 91 của hãng Sigma:

- Độ 0: Không có hạt bắt màu thuốc nhuộm.

- Độ 1: Ít hạt màu đỏ trên nguyên sinh chất, hạt mịn nhỏ, chiếm $\leq 1 / 3$ bào tương của tế bào.

- Độ 2: Nhiều hạt màu đỏ trên nguyên sinh chất, hạt trung bình, chiếm $1 / 3$ đến $3 / 4$ bào tương của tế bào.

- Độ 3: Nhiều hạt màu đỏ trên nguyên sinh chất, hạt to, chiếm hết bào tương của tế bào và che phủ một phần nhân tế bào.
- Độ 4: Nhiều hạt phủ kín nguyên sinh chất và nhân, hạt to.

Điểm nhuộm được tính theo công thức:

$\sum \mathrm{Y}($ điểm $)=\mathrm{Y}_{0} \mathrm{x}_{0}+\mathrm{Y}_{1} \times 1+\mathrm{Y}_{2} \mathrm{x}_{2}+\mathrm{Y}_{3}$ $\mathrm{x} 3+\mathrm{Y}_{4} \mathrm{x} 4$

Thực hiện nhuộm kỹ thuật photphataza sử dụng cơ chất tổng hợp được để khảo sát thời gian nhuộm tối ưu và $\mathrm{pH}$ nhuộm tối ưu.

Các dung dịch đệm sử dụng:

\begin{tabular}{ll}
\hline $\mathrm{PO}_{4}{ }^{3-} 0,0124 \mathrm{M}, \mathrm{pH}=7,4$ & (a) \\
\hline $\mathrm{PO}_{4}{ }^{3-} 0,0667 \mathrm{M}-\mathrm{NaF}, \mathrm{pH}=7,9$ & (b) \\
$\mathrm{PO}_{4}{ }^{3-} 0,0667 \mathrm{M}, \mathrm{pH}=8,0$ & (c) \\
$\mathrm{PO}_{4}{ }^{3-} 0,0667 \mathrm{M}, \mathrm{pH}=6,8$ & (d) \\
$\mathrm{PO}_{4}{ }^{3-} 0,0124 \mathrm{M}, \mathrm{pH}=5,4$ & (e) \\
Photphat axit, $\mathrm{pH}=5,2$ & (f) \\
Photphat kiềm, $\mathrm{pH}=10,4$ & (g) \\
Tris, $\mathrm{pH}=9,5$ & (h) \\
Veronal axetat, $\mathrm{pH}=9,799$ & (i) \\
\hline
\end{tabular}

Kết quả khảo sát được thể hiện trong các bảng 3-5.

\section{Thảo luận kết quả}

\subsection{Tổng hợp co chất Naphthol AS-X photphat}

Quy trình tổng hợp Naphtol AS-X photphat được thực hiện qua 3 giai đoạn theo [6]:

a. Tổng hợp 3-[( N-aryl) cacbamoyl] naphtalen-2-yl photphodiclorat:

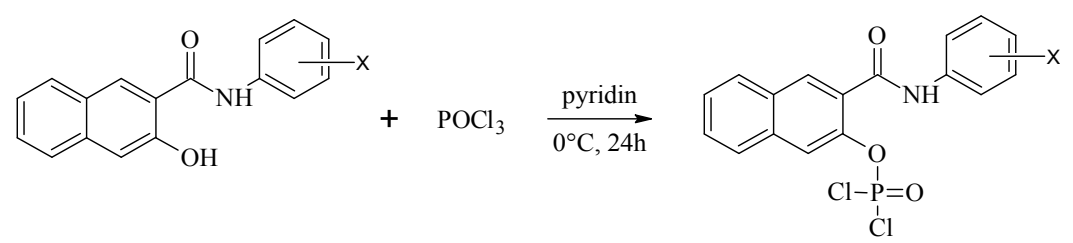

b. Tổng hợp dinatri-3-[( N-aryl) cacbamoyl] naphtalen-2-yl photphat.<smiles>[X]c1ccc(NC(=O)c2cc3ccccc3cc2OP(=O)(Cl)Cl)cc1</smiles>

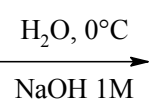<smiles>[M]OP(=O)(O)Oc1cc2ccccc2cc1C(=O)Nc1cccc([X])c1</smiles> 
c. Tổng hợp 3-[(N-aryl) cacbamoyl] naphtalen-2-yl dihidroxyphotphat.<smiles></smiles>

Theo quy trình thí nghiệm trên đã tổng hợp được 6 cơ chất với hiệu suất trong khoảng 40$50 \%$ và trong đó có 1 cơ chất là Naphtol $\mathrm{AS}$ BO photphat là một cơ chất mới (bảng 1).

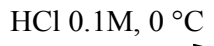<smiles>[X]c1ccc(NC(=O)c2cc3ccccc3cc2OP(=O)(O)O)cc1</smiles>

Độ tinh khiết của các cơ chất được kiểm tra bằng phổ $\mathrm{IR}$ và $\mathrm{MS}$ (bảng 2 ).

Bảng 1. Kết quả đã tổng hợp được 6 dẫn xuất naphtol AS-X photphat

\begin{tabular}{lll}
\hline Kí hiệu & Nhóm thế -X & Tên cơ chất \\
\hline I & $o-\mathrm{CH}_{3}$ & Naphtol AS-D photphat \\
II & $o-\mathrm{OCH}_{3}$ & Naphtol AS-OL photphat \\
III & $m-, o-\mathrm{OCH}_{3} ; p-\mathrm{Cl}$ & Naphtol AS-LC photphat \\
IV & $m-\mathrm{NO}_{2}$ & Naphtol AS-BS photphat \\
V & $m-\mathrm{Cl} ; o-\mathrm{OCH}_{3}$ & Naphtol AS-CA photphat \\
VI & $\mathrm{N}-$ naphtyl & Naphtol AS-BO photphat \\
\hline
\end{tabular}

Bảng 2. Hiệu suất, một số hằng số hóa lý, phổ IR và MS của các cơ chất đã tổng hợp được

\begin{tabular}{|c|c|c|c|c|c|}
\hline Kí hiệu & $\begin{array}{l}\mathrm{M} \\
(\mathrm{g} / \mathrm{mol})\end{array}$ & $\mathrm{H}(\%)$ & $\mathrm{T}_{\mathrm{nc}}{ }^{0} \mathrm{C}$ & $\operatorname{IR}\left(\mathrm{KBr} ; v, \mathrm{~cm}^{-1}\right)$ & $\begin{array}{l}\text { ESI-MS, } \\
\text { m/z [Itd] (\%) }\end{array}$ \\
\hline I & 357,30 & 44 & $100-103$ & $\begin{array}{l}3394,7(\mathrm{~N}-\mathrm{H}) ; 1651,1(\mathrm{C}=\mathrm{O}) \\
1232,5 ; 1166,9 ; 1062,8(\mathrm{P}-\mathrm{O} / \mathrm{C}- \\
\mathrm{O}) ; 3020,1\left(\mathrm{C}_{\mathrm{sp} 2}-\mathrm{H}\right)\end{array}$ & {$[\mathrm{M}-\mathrm{H}]^{-}=356,3$} \\
\hline II & 373,30 & 36 & 190-192 & $\begin{array}{l}3350,4(\mathrm{~N}-\mathrm{H}) ; 1641,4(\mathrm{C}=\mathrm{O}) \\
1261,4 ; 1168,9 ; 1053,1(\mathrm{P}-\mathrm{O} / \mathrm{C}- \\
\mathrm{O}) ; 3035,9 ; 3061,0\left(\mathrm{C}_{\mathrm{sp} 2}-\mathrm{H}\right)\end{array}$ & $\begin{array}{l}{[\mathrm{M}-\mathrm{H}]^{-}=371,9} \\
{[\mathrm{M}+\mathrm{H}]^{+}=373,9}\end{array}$ \\
\hline III & 437,77 & 24 & $155-157$ & $\begin{array}{l}3346,5(\mathrm{~N}-\mathrm{H}) ; 1625,9(\mathrm{C}=\mathrm{O}) \\
1240,2 ; 1178,5 ; 1068,5(\mathrm{P}-\mathrm{O} / \mathrm{C}- \\
\mathrm{O}) ; 3016,6 ; 3076,4\left(\mathrm{C}_{\mathrm{sp} 2}-\mathrm{H}\right)\end{array}$ & $\begin{array}{l}{[\mathrm{M}-\mathrm{H}]^{-}=435,8} \\
{[\mathrm{M}+\mathrm{H}]^{+}=437,9}\end{array}$ \\
\hline IV & 388,27 & 58 & $83-85$ & $\begin{array}{l}3329,1(\mathrm{~N}-\mathrm{H}) ; 1678,0(\mathrm{C}=\mathrm{O}) ; \\
1253,7 ; 1111,0 ; 1056,9(\mathrm{P}-\mathrm{O} / \mathrm{C}- \\
\mathrm{O}) ; 3070,6\left(\mathrm{C}_{\mathrm{sp} 2}-\mathrm{H}\right)\end{array}$ & $\begin{array}{l}{[\mathrm{M}-\mathrm{H}]^{-}=386,9} \\
{[\mathrm{M}+\mathrm{H}]^{+}=388,9}\end{array}$ \\
\hline $\mathrm{V}$ & 407,74 & 53 & $154-156$ & $\begin{array}{l}3367,7(\mathrm{~N}-\mathrm{H}) ; 1647,2(\mathrm{C}=\mathrm{O}) \\
1255,6 ; 1168,8 ; 1068,5(\mathrm{P}-\mathrm{O} / \mathrm{C}- \\
\mathrm{O}) ; 3064,8\left(\mathrm{C}_{\mathrm{sp} 2}-\mathrm{H}\right)\end{array}$ & $\begin{array}{l}{[\mathrm{M}-\mathrm{H}]^{-}=405,9} \\
{[\mathrm{M}+\mathrm{H}]^{+}=407,9}\end{array}$ \\
\hline VI & 393,33 & 56 & $141-143$ & $\begin{array}{l}3574,1(\mathrm{~N}-\mathrm{H}) ; 1662,6(\mathrm{C}=\mathrm{O}) ; \\
1247,9 ; 1166,9 ; 1087,8(\mathrm{P}-\mathrm{O} / \mathrm{C}- \\
\mathrm{O}) ; 3068,7\left(\mathrm{C}_{\mathrm{sp} 2}-\mathrm{H}\right)\end{array}$ & $\begin{array}{l}{[\mathrm{M}-\mathrm{H}]^{-}=391,9} \\
{[\mathrm{M}+\mathrm{H}]^{+}=394,0}\end{array}$ \\
\hline
\end{tabular}

Trên phổ IR có các hấp thụ đặc trưng cho dao động hóa trị N-H amit bậc 2 ở $3350 \mathrm{~cm}^{-1}$; dao động hóa trị $\mathrm{C}=\mathrm{O}$ của amit ở $1650 \mathrm{~cm}^{-1}$; dao động biến dạng của liên kết N-H ở 1530 $\mathrm{cm}^{-1}$ bị chồng chập lẫn vào vùng dao động hóa trị của liên kết $\mathrm{C}=\mathrm{C}$ của vòng thơm; các dao động hóa trị $\mathrm{C}_{\mathrm{sp}}{ }^{2}-\mathrm{H}$ cũng xuất hiện ở $3050 \mathrm{~cm}^{-1}$. 
Phổ MS của hợp chất Naphtol AS-X photphat cho nhiều phân mảnh do cấu trúc kém bền của phân tử. Các pic tương ứng với ion phân tử $[\mathrm{M}-\mathrm{H}]^{-}$và $[\mathrm{M}+\mathrm{H}]^{+}$phù hợp với phân tử khối của hợp chất tổng hợp được.<smiles>O=C(Nc1cccc2ccccc12)c1cc2ccccc2cc1OP(=O)(O)O</smiles>

Naphtol AS-BO photphat

Phổ ${ }^{1} \mathrm{H}-\mathrm{NMR}$ của Naphthol AS-BO photphat ( DMSO; $\delta$, ppm; J, Hz): 10.97 (s, 1H, $\mathrm{NH}), 8.42(\mathrm{~s}, 1 \mathrm{H}, \mathrm{H}-4), 8.30\left(\mathrm{~d},{ }^{3} J=9.0,1 \mathrm{H}, \mathrm{H}-\right.$ 5'), $8.07\left(\mathrm{~d},{ }^{3} \mathrm{~J}=8.0,1 \mathrm{H}, \mathrm{H}-5\right), 7.96(\mathrm{~d}, 2 \mathrm{H}, \mathrm{H}-$ 1, H-8'), 7.90 (dd, 2H, H-8, H-4'), 7.83 (d, ${ }^{3} \mathrm{~J}=$ 8.0, 1H, H-2'), 7.76 - 7.45 (m, 5H, H-3', H-6', H-7', H-6, H-7). Trên phổ ${ }^{1} \mathrm{H}-\mathrm{NMR}$ của Naphthol AS-BO photphat cho xuất hiện singlet tại 10.966 ppm của proton trong liển kết N-H (amit), không thấy xuất hiện proton nhóm $\mathrm{OH}$ của photphat, có lẽ do proton của $\mathrm{OH}$ dễ bị mất khi trong dung môi có vết nước.
Kết quả xác định phổ IR và MS cho thấy các cơ chất có độ tinh khiết cần thiết để tiến hành thí nghiệm nhuộn tế bào.

\subsection{Nhuộm kỹ thuật photphataza}

Các cơ chất tổng hợp được ở trên được đem đi nhuộm hóa học tế bào kỹ thuật nhuộm photphataza thấy rằng tất cả các cơ chất tổng hợp được đều cho kết quả dương tính đặc hiệu với các tế bào dòng bạch cầu: bạch cầu trung tính, bạch cầu ưa axit, bạch cầu ưa bazơ.

Sau khi thực hiện thí nghiệm khảo sát dung dịch đệm tối ưu, thời gian nhuộm chất cần phát hiện tối ưu, nghiên cứu đã thu được kết quả điều kiện nhuộm tối ưu là ở $37^{\circ} \mathrm{C}$, dung dịch đệm photphataza kiềm với thời gian nhuộm chất cần phát hiện là 60 phút.

Bảng kết quả nhuộm thử của cơ chất tổng hợp được tại điều kiện tối ưu so với mẫu đối chứng là cơ chất chuẩn Naphthol AS-BI photphat sản phẩm của Sigma Aldrich được trình bày trong bảng 4 .

Hình ảnh kết quả nhuộm trên mẫu máu ngoại vi của người khỏe mạnh cho kết quả dương tính đặc hiệu trên dòng tế bào bạch cầu của cơ chất tổng hợp được trình bày trong bảng 5 .

Bảng 3. Bảng kết quả thí nghiệm khảo sát dung dịch đệm tối ưu (\%)

\begin{tabular}{|c|c|c|c|c|c|c|}
\hline Hệ đệm & I & II & III & IV & V & VI \\
\hline (a) & $\begin{array}{l}80 \\
(20,0 \%)\end{array}$ & $\begin{array}{l}78 \\
(19,5 \%)\end{array}$ & $\begin{array}{l}56 \\
(14,0 \%)\end{array}$ & $\begin{array}{l}100 \\
(25 \%)\end{array}$ & $\begin{array}{l}89 \\
(22,25 \%)\end{array}$ & $\begin{array}{l}85 \\
(21,25 \%)\end{array}$ \\
\hline (b) & $\begin{array}{l}75 \\
(18,75 \%)\end{array}$ & $\begin{array}{l}80 \\
(20,0 \%)\end{array}$ & $\begin{array}{l}65 \\
(16,25 \%)\end{array}$ & $\begin{array}{l}85 \\
(21,25 \%)\end{array}$ & $\begin{array}{l}88 \\
(22,0 \%)\end{array}$ & $\begin{array}{l}75 \\
(18,75 \%)\end{array}$ \\
\hline (c) & $\begin{array}{l}82 \\
(20,0 \%)\end{array}$ & $\begin{array}{l}110 \\
(27,5 \%)\end{array}$ & $\begin{array}{l}80 \\
(20,0 \%)\end{array}$ & $\begin{array}{l}109 \\
(27,25 \%)\end{array}$ & $\begin{array}{l}85 \\
(21,25 \%)\end{array}$ & $\begin{array}{l}80 \\
(20,25 \%)\end{array}$ \\
\hline (d) & $\begin{array}{l}76 \\
(19,0 \%)\end{array}$ & $\begin{array}{l}90 \\
(22,5 \%)\end{array}$ & $\begin{array}{l}40 \\
(10,0 \%)\end{array}$ & $\begin{array}{l}95 \\
(23,75 \%)\end{array}$ & $\begin{array}{l}60 \\
(15,0 \%)\end{array}$ & $\begin{array}{l}65 \\
(16,25 \%)\end{array}$ \\
\hline (e) & $\begin{array}{l}50 \\
(12,5 \%)\end{array}$ & $\begin{array}{l}70 \\
(17,5 \%)\end{array}$ & Âm tính & $\begin{array}{l}60 \\
(36,26 \%)\end{array}$ & Âm tính & Âm tính \\
\hline (f) & Âm tính & Âm tính & Âm tính & Âm tính & Âm tính & Âm tính \\
\hline (g) & $\begin{array}{l}114 \\
(28,5 \%)\end{array}$ & $\begin{array}{l}145 \\
(36,25 \%)\end{array}$ & $\begin{array}{l}72 \\
(18,0 \%)\end{array}$ & $\begin{array}{l}133 \\
(33,25 \%)\end{array}$ & $\begin{array}{l}100 \\
(25,0 \%)\end{array}$ & $\begin{array}{l}117 \\
(29,25 \%)\end{array}$ \\
\hline (h) & $\begin{array}{l}66 \\
(16,5 \%)\end{array}$ & $\begin{array}{l}100 \\
(25,0 \%)\end{array}$ & $\begin{array}{l}60 \\
(15,0 \%)\end{array}$ & $\begin{array}{l}95 \\
(23,75 \%)\end{array}$ & $\begin{array}{l}60 \\
(15,0 \%)\end{array}$ & $\begin{array}{l}75 \\
(18,75 \%)\end{array}$ \\
\hline (i) & $\begin{array}{l}96 \\
(24,0 \%)\end{array}$ & $\begin{array}{l}120 \\
(30,0 \%)\end{array}$ & $\begin{array}{l}80 \\
(20,0 \%)\end{array}$ & $\begin{array}{l}115 \\
(28.75 \%)\end{array}$ & $\begin{array}{l}76 \\
(19,0 \%)\end{array}$ & $\begin{array}{l}75 \\
(18,75 \%)\end{array}$ \\
\hline
\end{tabular}


Bảng 4. Kết quả nhuộm bằng cơ chất naphtol AS-X tổng hợp được so với sản phẩm của Sigma

\begin{tabular}{|c|c|c|c|c|c|c|c|c|}
\hline Cơ chất & 5114 & 6103 & 5030 & 5041 & 6863 & 5077 & 5036 & 6844 \\
\hline $\begin{array}{l}\text { Naphthol AS-BI } \\
\text { photphat - Sigma }\end{array}$ & $\begin{array}{l}67 \\
16.75 \%\end{array}$ & $\begin{array}{l}137 \\
34.25 \%\end{array}$ & $\begin{array}{l}226 \\
56.50 \%\end{array}$ & $\begin{array}{l}103 \\
25.75 \%\end{array}$ & $\begin{array}{l}87 \\
21.75 \%\end{array}$ & $\begin{array}{l}201 \\
50.25 \%\end{array}$ & $\begin{array}{l}378 \\
94.50 \%\end{array}$ & $\begin{array}{l}180 \\
45.00 \%\end{array}$ \\
\hline I & $\begin{array}{l}87 \\
21.75 \%\end{array}$ & $\begin{array}{l}97 \\
24.25 \%\end{array}$ & $\begin{array}{l}150 \\
37.50 \%\end{array}$ & $\begin{array}{l}83 \\
20.75 \%\end{array}$ & $\begin{array}{l}77 \\
19.25 \%\end{array}$ & $\begin{array}{l}90 \\
22.50 \%\end{array}$ & $\begin{array}{l}286 \\
71.50 \%\end{array}$ & $\begin{array}{l}135 \\
33.75 \%\end{array}$ \\
\hline II & $\begin{array}{l}95 \\
23.75 \%\end{array}$ & $\begin{array}{l}116 \\
29.00 \%\end{array}$ & $\begin{array}{l}160 \\
40.00 \%\end{array}$ & $\begin{array}{l}113 \\
28.25 \%\end{array}$ & $\begin{array}{l}94 \\
23.50 \%\end{array}$ & $\begin{array}{l}165 \\
41.25 \%\end{array}$ & $\begin{array}{l}372 \\
93.00 \%\end{array}$ & $\begin{array}{l}186 \\
46.50 \%\end{array}$ \\
\hline III & $\begin{array}{l}89 \\
22.25 \%\end{array}$ & $\begin{array}{l}103 \\
25.75 \%\end{array}$ & $\begin{array}{l}204 \\
51.00 \%\end{array}$ & $\begin{array}{l}88 \\
22.00 \%\end{array}$ & $\begin{array}{l}86 \\
21.50 \%\end{array}$ & $\begin{array}{l}135 \\
33.75 \%\end{array}$ & $\begin{array}{l}364 \\
91.00 \%\end{array}$ & $\begin{array}{l}167 \\
41.75 \%\end{array}$ \\
\hline IV & $\begin{array}{l}75 \\
18.75 \%\end{array}$ & $\begin{array}{l}139 \mathrm{r} \\
34.75 \%\end{array}$ & $\begin{array}{l}126 \\
31.50 \%\end{array}$ & $\begin{array}{l}96 \\
24.00 \%\end{array}$ & $\begin{array}{l}85 \\
21.25 \%\end{array}$ & $\begin{array}{l}150 \\
37.50 \%\end{array}$ & $\begin{array}{l}375 \\
93.75 \%\end{array}$ & $\begin{array}{l}199 \\
49.75 \%\end{array}$ \\
\hline V & $\begin{array}{l}84 \\
21.00 \%\end{array}$ & $\begin{array}{l}127 \\
31.75 \%\end{array}$ & $\begin{array}{l}212 \\
53.00 \%\end{array}$ & $\begin{array}{l}108 \\
27.00 \%\end{array}$ & $\begin{array}{l}66 \\
16.50 \%\end{array}$ & $\begin{array}{l}93 \\
23.25 \%\end{array}$ & $\begin{array}{l}338 \\
84.50 \%\end{array}$ & $\begin{array}{l}213 \\
53.25 \%\end{array}$ \\
\hline VI & $\begin{array}{l}99 \\
24.75 \%\end{array}$ & $\begin{array}{l}116 \\
29.00 \%\end{array}$ & $\begin{array}{l}217 \\
54.25 \%\end{array}$ & $\begin{array}{l}116 \\
29.00 \%\end{array}$ & $\begin{array}{l}120 \\
30.00 \%\end{array}$ & $\begin{array}{l}163 \\
40.75 \%\end{array}$ & $\begin{array}{l}350 \\
87.50 \%\end{array}$ & $\begin{array}{l}163 \\
40.75 \%\end{array}$ \\
\hline
\end{tabular}

Bảng 5. Hình ảnh nhuộm thử trên mẫu bệnh phẩm bằng cơ chất naphtol AS-X

\begin{tabular}{|l|l|l|l|l|l|l|}
\hline $\begin{array}{l}\text { Cơ chất tổng } \\
\text { hợp }\end{array}$ & I & II & III & IV & V & VI \\
\hline $\begin{array}{l}\text { Hình ảnh tế } \\
\text { bào bạch cầu } \\
\text { dương tính } \\
\text { nhuộm } \\
\text { photphataza }\end{array}$ & & & & & & \\
\hline
\end{tabular}

\section{Kết luận}

1. Đã tổng hợp được 6 dẫn xuất naphtol AS thế photphat làm cơ chất nhuộn photphataza đặc hiệu bạch cầu người, trong đó có 1 hợp chất mới; đã cải tiến việc tinh chế naphtol AS-X photphat so với quy trình trong tài liệu [6] bằng cách hòa tan kết tủa trong hỗn hợp dung môi nước: THF tỷ lệ 1:5. Kểt quả thu được sản phấm naphtol AS-X photphat có độ tinh khiết cao.

2. Đã tiến hành nhuộm thử nghiệm photphataza đặc hiệu tế bào bạch cầu người bằng các dẫn xuất naphtol $\mathrm{AS}-\mathrm{X}$ photphat tổng hợp được. Kết quả cho thấy các có chất tổng hợp được có độ nhạy và tính đặc hiệu đối với các tế bào bạch cầu trung tính, bạch cầu ưa axit và bạch cầu ưa bazơ tương đương với các cơ chất tương ứng nhập ngoại.

\section{Tài liệu tham khảo}

[1] Đỗ Thị Vinh An, Phạm Quang Vinh, Phan Văn Chi, Nguyễn Thị Bích Nhi, "Bước đầu tìm hiểu một số biến đổi protein ở bệnh nhân lơxêmi cấp dòng lympho tại khoa Huyết học Truyền máu bệnh viện Bạch Mai", Tạp chí Y học Việt Nam,T.373 (2), 267-270, (2010).

[2] Rebecca L. Siegel, Kimberly D. Miller and Ahmedin Jemal, "Cancer Statistics", CA cancer J Clin 2016, vol 66, pp. 7-30, (2016).

[3] Bennett JM., Catovsky D., Daniel MT., "Proposals for the classification of the acute leukaemias. French-American-British (FAB) cooperative group", Br. J. Haematol, Vol.33 (4), 451-458, (1976).

[4] Trần Văn Tính, Tổng hợp cơ chất, chế tạo kít và nghiên cứu điều kiện tối ưu để nhuộm tế bào phục vụ chẩn đoán bệnh ung thư bạch cầu người, Luận án Tiến sĩ hóa học, trường Đại học Khoa học Tự nhiên-ĐHQGHN, (2012). 
[5] Trần Văn Tính, Bùi Thanh Hương, Nguyễn Đắc Thảo, Nghiên cứu chế tạo bộ kit nhuộm hóa học tế bào để chẩn đoán các dòng tế bào trong bệnh ung thư máu, Bệnh viện 19-8, Bộ công an, (2015).
[6] Vaughan A., Guilbault GG., and Hackney D., Fluorometric Methods for Analysis of Acid and Alkaline Photphataza, Analytical chemistry, Vol.43( 6), 721-724, (1971).

\title{
Synthesis of Naphthol as-substituted Phosphateusing as Substrates for Phosphatase Inhuman Leukemia Staining
}

\author{
Tran Thi Hoa ${ }^{1}$, Tran Thi Thanh Tam ${ }^{1}$, \\ Nguyen Dinh Duy ${ }^{3}$, Luu Van Boi ${ }^{1}$, Tran Van Tinh ${ }^{2}$ \\ ${ }^{I}$ Faculty of Chemistry, VNU University of Science, 19 Le Thanh Tong, Hanoi, Vietnam \\ ${ }^{2}$ Blood transfusion- Hematology Center, 19-8 Hospital \\ ${ }^{3}$ HUS High School for Gifted Students, VNU University of Science, 334 Nguyen Trai, Hanoi, Vietnam
}

\begin{abstract}
Naphthol AS-BI phosphate is used as substrate to classify leukocyte cell lines and differentiate T lymphocytes in acute leukemia. In order to expand the source of high sensitivity and specificity substrates with a reasonable price, in this study were synthesized 3-[(N-aryl)carbamoyl]naphthalen-2-yl dihydroxyphosphate derivatives ( naphthol AS-X phosphates) by reaction of naphthol AS-X with $\mathrm{POCl}_{3}$ then hydrolyzed. The results of specific phosphotase cells staining using synthesized 6 naphthol AS-X phosphate derivatives showed that all of the substrates are positive with neutrophil, eosinophil and basephil.
\end{abstract}

Keywords: Naphthol AS-BI phosphate, Alkaline phosphatase, acute leukemia. 